\title{
Usefulness of Chromic Oxide Index Method for Determination of Digestibility of Nutrients in Feeds for Thoroughbreds
}

\author{
Hisao TAKAGI ${ }^{1}$, Yasushi HASHIMOTO ${ }^{1 *}$, Chisato YONEMOCHI $^{1}$, Yo ASAI $^{2}$, \\ Tatsuyuki YOSHIDA ${ }^{3}$, Yoshiyuki OHTA ${ }^{3}$, Teru ISHIBASHI ${ }^{3}$ and Reiko WATANABE ${ }^{4}$ \\ ${ }^{1}$ Japan Scientific Feeds Association, 1-2 Kanda-Surugadai, Chiyoda-ku, Tokyo 101-0062, ${ }^{2}$ Hidaka Yearling \\ Training Farm, Japan Racing Association, 535-13 Nishicha, Urakawa-cho Urakawa-gun Hokkaido 057-0171, \\ ${ }^{3}$ Nippon Veterinary and Animal Science University, 1-7-1 Kyounan-cho, Musashino-shi, Tokyo 180-8680 and \\ ${ }^{4}$ Niigata Women's College, 471 Ebigase Niigata-shi Niigata 950-8060, Japan
}

In order to confirm the usefulness of chromic oxide as an indicator in the determination of digestibility of nutrients in feeds, two experiments were conducted on 4 male thoroughbreds 5 to 9 years old. In Experiment 1, in order to determine the timing of sampling, the time course of fecal chromic oxide after changing feeds and daily variation of the fecal concentration of chromic oxide were observed. Horses were given Feeds 1 and 2 containing $0.2 \%$ chromic oxide for 7 days. Feces were collected in feces bags. In Experiment 2, horses were supplied Feeds 1 and 2 for 10 days and feces were collected in the same way as in Experiment 1 for the total feces collection method and about $200 \mathrm{~g}$ offeces at 7:00 and 19:00 for the chromic oxide index method for the last 4 days. Fecal contents of chromic oxide reached a plateau at $48 \mathrm{hr}$ after feeding Feeds 1 and 2 containing chromic oxide and remained constant after that. The digestibility of crude protein, ether extract, nitrogen free extract and crude fiber determined by the chromic oxide index method agreed well with that by the total feces collection method in both feeds. Because the timing of excretion of feces was relatively constant in the morning and evening feeding, it was easy to collect feces directly from the anus with a bucket.

Key words: chromic oxide, digestibility, index method, thoroughbreds
J. Equine Sci.

Vol. 13, No. 1

pp. 19-22, 2002
In order to feed horses effectively, data on requirements of nutrients and contents and digestibility or availability of nutrients in feedstuffs are essential. There are, however, few studies on requirements of nutrients and digestibility of feedstuffs in thoroughbreds. Parallel to determination of requirements of nutrients of horses, the digestibility of feedstuffs commonly used in horses has to be clarified for scientific and economical formulation of feeds instead of traditional and experiential formulation of feeds.

The total feces collection method is one of the most exact methods for the determination of digestibility of feedstuffs in all animals, but adult thoroughbreds excrete daily more than $10 \mathrm{~kg}$ of feces, as observed in

This article was accepted April 4, 2002.

${ }^{*}$ Corresponding author. the previous experiment [10]. Therefore, it was so laborious to collect all feces in feces bags that it was desired to develop a method that was easy and not laborious. In order to decrease labor and stress in the animals, index methods are utilized widely in many species to determine digestibility of feedstuffs and feeds by means of indicators such as chromic oxide, acid insoluble ash, soluble ethylene glycol, polyethylene grain, isotope ${ }^{90} \mathrm{Y}$, chromogen and lignin [5]. Among them, chromic oxide is used most popularly in many species.

In the case of animals with cannule [5], it is possible to estimate the digestibility of feeds by using nylon bags. In the case of pigs [4] and chicken [8], it is possible to predict the digestibility of CP and dry matter in feeds by an in vitro method using the intestinal fluid of pigs, but there are no available reports on the attachment of cannules to digestive tracts, in vitro methods or index 
Table 1. Contents of nutrients in feedstuffs and feeds (\%)

\begin{tabular}{lrrrrrrr}
\hline & Moisture & CP & EE & NFE & CF & CA & $\mathrm{Cr}_{2} \mathrm{O}_{3}$ \\
\hline Commercial feed (C) & 10.8 & 12.0 & 4.4 & 49.1 & 21.0 & 7.6 & - \\
Timothy hay (T) & 9.0 & 5.4 & 1.8 & 51.1 & 28.1 & 4.6 & - \\
Feed 1 (T:C=7:3) & 10.4 & 10.4 & 3.6 & 47.1 & 22.3 & 6.0 & 0.2 \\
Feed 2 (T:C=3:7) & 10.7 & 7.4 & 2.9 & 49.5 & 24.0 & 5.6 & 0.2 \\
\hline
\end{tabular}

$\mathrm{CP}=$ crude protein, $\mathrm{EE}=$ ether extract, $\mathrm{NFE}=$ nitrogen free extract, $\mathrm{CF}=$ crude fiber and $\mathrm{CA}=$ crude $\mathrm{ash}$.

methods in horses.

In this study, therefore, two experiments were conducted to confirm the usefulness of the index method with chromic oxide for the determination of digestibility of nutrients in feedstuffs and feeds in adult thoroughbreds. In Experiment 1, the time until the fecal chromic oxide concentration reached a plateau and the width of variance of the fecal concentration of chromic oxide were observed. In Experiment 2, the digestibilities of two feeds determined by the total collection method and chromic oxide index method were compared.

\section{Materials and Methods}

Four male thoroughbreds 5 to 9 years old weighing $511 \pm 56 \mathrm{~kg}$ were confined individually in rooms with a floor covered with sawdust. In Experiment 1, they were given free access to Feed 1 without chromic oxide and water and accustomed to the new environment for 20 days. Then they were given Feed 1 with chromic oxide for 7 days. The horses were then given Feed 2 deprived of chromic oxide for 5 days, and then Feed 2 with chromic oxide for 7 days. In Experiment 2, they were given Feed 1 with chromic oxide for 10 days and then Feed 2 with chromic oxide for 10 days. Feed 1 consisted of $30.0 \%$ timothy hay, $69.8 \%$ commercial horse feed and $0.2 \%$ chromic oxide or mineral mixture. Feed 2 consisted of $70.0 \%$ timothy hay, $29.8 \%$ commercial feed and $0.2 \%$ chromic oxide or mineral mixture. Timothy hay was cut into 2 to $3 \mathrm{~cm}$ length. The commercial feed was ground and had chromic oxide added to a $0.2 \%$ final concentration in both feeds. Half amounts of the rations were supplied at 7:00 and 15:00. The amount of ration was estimated to satisfy the maintenance requirements of $\mathrm{DE}$ recommended by the NRC (1989) [7] and Japanese Feeding Standard for Horses [3, JFS]. DE values were cited from the table in the Japanese Feeding Standards for Beef Cattle [1]. Feeds 1 and 2 contained 10.7 and $7.4 \%$ crude protein (CP), 2.37 and 2.42 Mcal digestive energy (DE) / kg, respectively.

Horses had a mask attached to prevent coprophagy after consuming all the feeds supplied. In Experiment 1, feces were collected at $4 \mathrm{hr}$ intervals from 7:00 to 19:00 and once between 19:00 and 7:00. At each sampling time, the feces collected were mixed and 1/ 15 of them was dried at $60^{\circ} \mathrm{C}$ in a ventilator and ground for the determination of nutrients and chromic oxide. All dried feces were mixed and ground through a $2 \mathrm{~mm}$ screen for chemical analyses. In Experiment 2, for the total collection method, feces were collected and treated in the same way as in Experiment 1. For the chromic oxide index method, about $200 \mathrm{~g}$ of feces were chosen from mixed samples at 7:00 and 19:00. After drying, the collected feces were treated in the same way.

In both experiments, the contents of moisture, CP, ether extract (EE), nitrogen free extract (NFE), crude fiber (CF), crude ash (CA), gross energy (GE) and chromic oxide in feedstuffs and feces were analyzed by the methods described by AOAC [2].

The data were analyzed by one-way ANOVA using the General Linear Model procedure of SAS ${ }^{\circledR}$, followed by Tukey's multiple range test [9]. Statements of significance were based on $p<0.05$ unless otherwise stated.

\section{Results and Discussion}

Throughout the long experimental period, all the horses looked healthy and initial body weights were maintained constant. These results indicated that the DE supplied was enough for the maintenance of body weight.

The period until all feeds supplied were consumed is shown in Fig. 1. Even when the same amount and quality of feeds were supplied, it took two times longer to consume the feeds supplied in the morning than to 


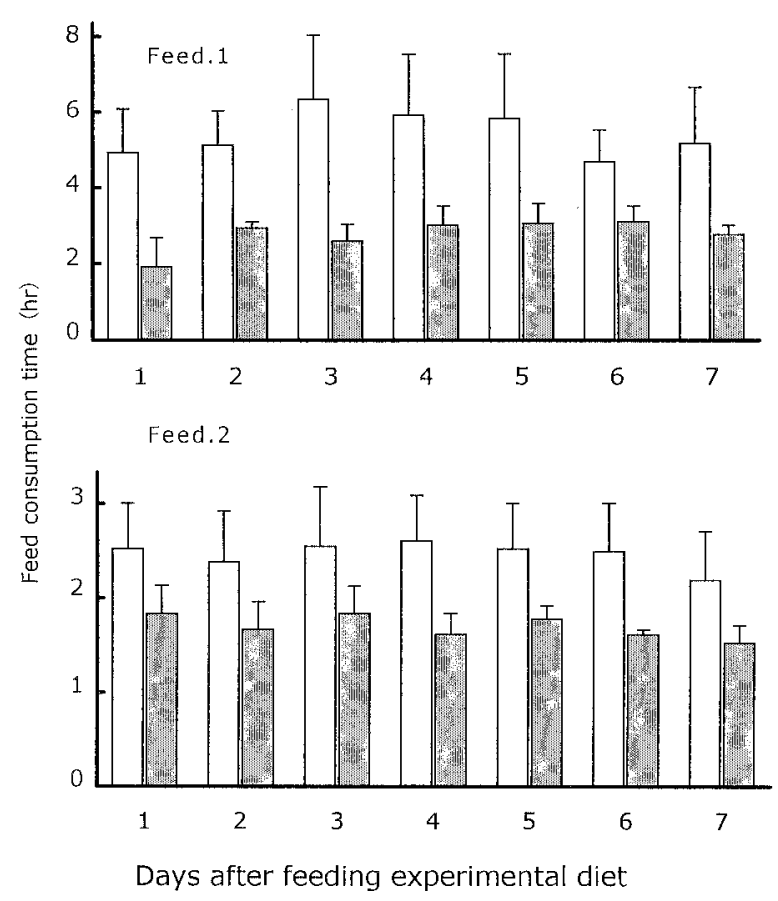

Fig. 1. Time course of feed consumption time after feeding experimental feeds in the morning (white) and evening (black). Each value is the mean and SE for 4 horses.

in the evening. But it was unclear which was better: to supply the same amount of feed or a different amount of feed within the same time morning and evening.

The daily amount of feces for 7 days after switching to experimental feeds remained relatively constant at $11.4 \pm 0.9 \mathrm{~kg} /$ day for Feed 1 and $10.6 \pm 0.6 \mathrm{~kg} /$ day for Feed 2, respectively (Fig. 2).

The amounts of feces collected at $4 \mathrm{hr}$ intervals from 7:00 to 19:00 during the daytime were estimated to be $0.60 \pm 0.23 \mathrm{~kg} / \mathrm{hr}$ for Feed 1 and $0.50 \pm 0.18 \mathrm{~kg} / \mathrm{hr}$ for Feed 2, respectively. Between 19:00 and 7:00, the amount of feces was more than twice of that in the daytime, but that expressed as $\mathrm{kg} / \mathrm{hr}$ was $0.36 \pm 0.13$ $\mathrm{kg} / \mathrm{hr}$ for Feed 1 and $0.39 \pm 0.05 \mathrm{~kg} / \mathrm{hr}$ for Feed 2, which were about half of those in the daytime for Feed 2.

In other species, there were differences in periods until the fecal chromic oxide concentration reached a constant level [5]. In the case of poultry and pigs [5], the feed passes rapidly through the digestive canal within a day and the fecal chromic oxide concentration becomes constant within $48 \mathrm{hr}$. In the case of ruminants [6], it took more than 4 days until the

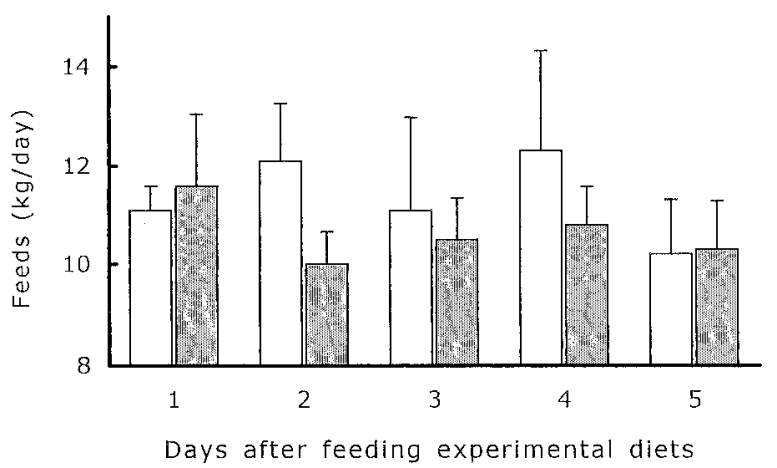

Fig. 2. Daily amount of feces for 5 days for Feeds 1 (white) and 2 (black) in Experiment 1.

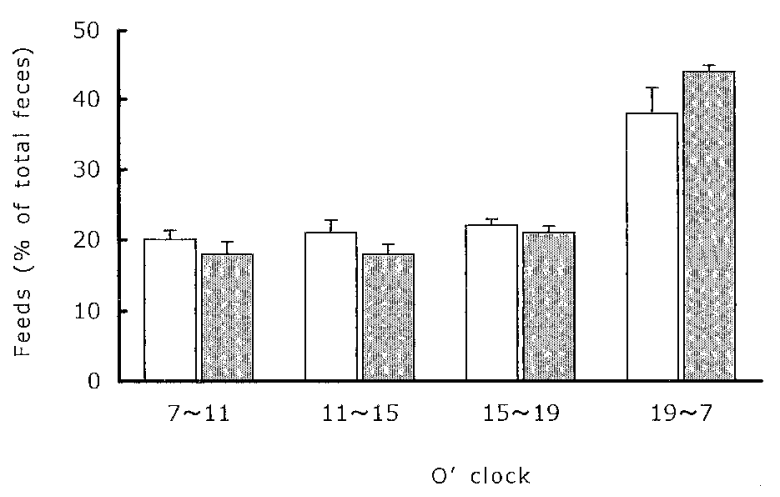

Fig. 3. Diurnal time course of feces of horses fed Feeds 1 (white) and 2 (black) in Experiment 1.

concentration of chromic oxide became constant after the feed containing chromic oxide was fed. As shown in Fig. 3, after switching the feeds without chromic oxide to feeds with chromic oxide, the fecal chromic oxide concentration increased until $48 \mathrm{hr}$ and then remained constant in both feeds. Thus it was possible to conclude that fecal samples had to be taken for at least 3 days after changing the feeds, as far as the same amount of feed was supplied.

Although it was not confirmed for how many days the feces samples had to be taken, especially when the composition of feeds was changed drastically, it was decided that feces had to be taken for 4 days after changing feeds, because the daily variation in the fecal concentration of chromic oxide was relatively constant, as shown in Fig. 4.

The determined digestibility of Feeds 1 and 2 is summarized in Table 2. The digestibility of CP, EE, NFE and CF in Feeds 1 and 2 determined by the 
Table 2. Digestibility of nutrients in experimental feeds determined by the total collection method and index method in Experiment 2 (\%)

\begin{tabular}{llcccc}
\hline & Method & CP & EE & NFE & CF \\
\hline \multirow{2}{*}{ Feed 1 } & Total & $70.7 \pm 2.7$ & $58.8 \pm 1.6$ & $70.9 \pm 1.5$ & $35.6 \pm 6.2$ \\
& Index & $70.7 \pm 0.8$ & $56.9 \pm 2.5$ & $69.4 \pm 0.8$ & $35.5 \pm 2.1$ \\
Feed 2 & Total & $65.0 \pm 1.8$ & $39.5 \pm 3.7$ & $61.9 \pm 0.3$ & $39.3 \pm 2.0$ \\
& Index & $59.0 \pm 2.7$ & $37.4 \pm 3.6$ & $65.0 \pm 0.8$ & $37.1 \pm 1.0$ \\
\hline
\end{tabular}

Values are the means \pm SE for four horses. See abbreviations in Table 1 .

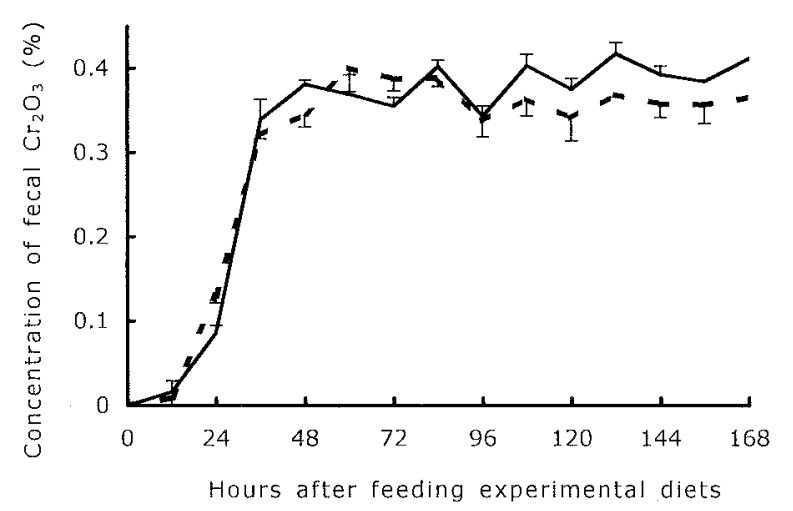

Fig. 4. Time course of fecal chromic oxide concentration after feeding Feeds 1 (solid) and 2 (broken) in Experiment 1.

chromic oxide index method agreed well with those by the total feces collection method. These results indicated that the chromic oxide index method was useful for determining the digestibility of nutrients in feeds as in many other species [5].

Because horses excreted feces at a relatively constant time after supplying the feed in the morning and evening, it was easy to collect feces directly from the anus with a bucket.

\section{References}

1. Agriculture, Forestry and Fisheries Research Council Secretariat, Ministry of Agriculture,
Forestry and Fisheries 2000. Japanese Feeding Standard for Beef Cattle.

2. Association of Official Analytical Chemists 1995. Official Methods of Analysis. 15th Rev. Ed. AOAC, Washington, D. C.

3. Equine Research Institute 1998. Japanese Feeding Standard for Horses. Japan Racing Association.

4. Furuya, S., Sakamoto, K, and Takahashi, M. 1979. A new in vitro method for the estimation of digestivity using the intestinal fluid of the pig. Br.J. Nutr. 41: 511-520.

5. Ishibashi, T. 2001. Experimental Methods for Animal Nutrition, Yokendo, Tokyo.

6. Kameoka, K., Takahashi, S., and Morimoto, H. 1956. Variation in the excretion of chromic oxide by ruminants. J. Dairy Sci. 39: 462-467.

7. National Research Council 1989. Nutrient Requirements of Horses. 5th Rev. Ed. National Academy Press, Washington, D. C.

8. Sakamoto, K., Asano, T., Furuya, S., and Takahashi, M. 1980. Estimation of in vivo digestibility with the laying hen by an in vitro method using the intestinal fluid of the pig. Br. J. Nutr. 43: 389-391.

9. SAS $^{\circledR}$ Institute 1995. SAS User's Guide. Ver. 6th Ed. SAS Institute Inc. Cary. NY.

10. Takagi, H., Hashimoto, Y., Yonemochi, T., Asai, H., Yoshida, T., Ohta, Y., Ishibashi, T., and Watanabe, R. 2001. Digestibility of hays determined by total feces collection method in Thoroughbreds. J. Equine Sci. (under contribution). 